\section{(2) OPEN ACCESS}

\title{
Risk of venous thromboembolism in knee, hip and hand osteoarthritis: a general population-based cohort study
}

\author{
Chao Zeng, ${ }^{1,2,3,4,5}$ Kim Bennell, ${ }^{6}$ Zidan Yang, ${ }^{4}$ Uyen-Sa D T Nguyen, ${ }^{7} \mathrm{Na}$ Lu, ${ }^{8}$ \\ Jie Wei, ${ }^{2,3,9}$ Guanghua Lei $\odot,{ }^{1,4,5}$ Yuqing Zhang $\circledast^{2,3}$
}

\begin{abstract}
Handling editor Josef $S$
Smolen

- Additional material is

published online only. To view please visit the journal online (http://dx.doi.org/10.1136/ annrheumdis-2020-217782).
\end{abstract}

For numbered affiliations see end of article.

\section{Correspondence to}

Professor Guanghua Lei,

Department of Orthopaedics, Xiangya Hospital, Central South University, Changsha, China; lei_guanghua@csu.edu.cn and Professor Yuqing Zhang, Division of Rheumatology, Allergy, and Immunology, Department of Medicine, Massachusetts General Hospital, Harvard Medical School, Boston, USA yzhang108@mgh.harvard.edu

Received 28 April 2020 Revised 29 July 2020 Accepted 3 August 2020

Published Online First 16 September 2020
Check for updates

(C) Author(s) (or their employer(s)) 2020. Re-use permitted under CC BY-NC. No commercial re-use. See rights and permissions. Published by BMJ.

To cite: Zeng $C$, Bennell $\mathrm{K}$, Yang Z, et al. Ann Rheum Dis 2020;79:1616-1624.

\section{ABSTRACT}

Objectives Osteoarthritis is a leading cause of immobility and joint replacement, two strong risk factors for venous thromboembolism (VTE). We aimed to examine the relation of knee, hip and hand osteoarthritis to the risk of VTE and investigate joint replacement as a potential mediator.

Methods We conducted three cohort studies using data from The Health Improvement Network. Up to five individuals without osteoarthritis were matched to each case of incident knee ( $n=20696)$, hip $(n=10$ 411 ) or hand ( $n=6329$ ) osteoarthritis by age, sex, entry time and body mass index. We examined the relation of osteoarthritis to VTE (pulmonary embolism and deep vein thrombosis) using a multivariable Cox proportional hazard model.

Results VTE developed in 327 individuals with knee osteoarthritis and 951 individuals without osteoarthritis (2.7 vs 2.0 per 1000 person-years), with multivariable-adjusted HR being $1.38(95 \% \mathrm{Cl} 1.23$ to 1.56). The indirect effect (HR) of knee osteoarthritis on VTE through knee replacement was 1.07 (95\% Cl 1.01 to 1.15 ), explaining $24.8 \%$ of its total effect on VTE. Risk of VTE was higher in hip osteoarthritis than non-osteoarthritis (3.3 vs 1.8 per 1000 person-years; multivariable-adjusted $\mathrm{HR}=1.83,95 \% \mathrm{Cl} 1.56$ to 2.13 ). The indirect effect through hip replacement yielded an HR of 1.14 (95\% Cl 1.04 to 1.25$)$, explaining $28.1 \%$ of the total effect. No statistically significant difference in VTE risk was observed between hand osteoarthritis and non-osteoarthritis (1.5 vs 1.6 per 1000 person-years; multivariable-adjusted $\mathrm{HR}=0.88,95 \% \mathrm{Cl} 0.67$ to 1.16$)$. Conclusion Our large population-based cohort study provides the first evidence that knee or hip osteoarthritis, but not hand osteoarthritis, was associated with an increased risk of VTE, and such an association was partially mediated through knee or hip replacement.

\section{INTRODUCTION}

Osteoarthritis (OA) is a common joint disorder, often affecting the knee, hip and hand, and is a leading cause of pain and disability. ${ }^{1}$ The WHO estimated that approximately $80 \%$ of patients with knee or hip OA have movement limitation and $25 \%$ are unable to perform their major daily-living activities. $^{2}$

Venous thromboembolism (VTE) is a common thromboembolic condition and potentially fatal disorder. Approximately 30\% of patients with pulmonary embolism (PE) die within the first year

\section{Key messages}

What is already known about this subject?

- Osteoarthritis (OA) is a leading cause of immobility and joint replacement, two strong risk factors for venous thromboembolism (VTE); however, no study has examined the association between $\mathrm{OA}$ and risk of VTE.

- To date, patients with OA have hardly been considered a high-risk population for VTE.

What does this study add?

- Our novel findings showed that the risk of incident VTE increased approximately $40 \%$ among individuals with knee $\mathrm{OA}$ and $80 \%$ among individuals with hip OA compared with those without OA.

- An increased risk of VTE in knee or hip OA was partly mediated through knee or hip replacement.

How might this impact on clinical practice or future developments?

- If our findings are confirmed by other studies, it will help identify a large proportion of high-risk population for VTE given that knee and hip OA are common among older individuals and have a growing prevalence due to the global ageing population and obesity epidemic.

after PE diagnosis. ${ }^{3}$ Strong risk factors for VTE include immobility and surgery. ${ }^{3}$ Thus, one would expect that OA, especially knee or hip OA, may be associated with a high risk of VTE through immobility and knee or hip joint replacement, a common surgery for advanced OA disease. Conversely, compared with knee and hip OA, hand OA is less likely to lead to immobility or lower-limb joint replacement; thus, individuals with hand OA may not experience a higher risk of VTE as those with knee or hip OA when compared with the general population. Although OA is a common disease and VTE is a potentially fatal condition, to our knowledge, no study has specifically examined the association between OA and risk of VTE.

We conducted three matched cohort studies to compare the risk of VTE, as well as PE and deep vein thrombosis (DVT) separately, among patients with knee, hip or hand OA with that among individuals without $\mathrm{OA}$ in a general population. 
In addition, we assessed the extent to which the association of knee or hip OA with VTE was mediated by knee or hip replacement.

\section{METHODS}

\section{Data source}

We used data from The Health Improvement Network (THIN), which is a prospectively gathered, anonymised medical database derived from the records of general practitioners (GPs) in the UK. It draws approximately 17 million participants from 790 general practices and is representative of the UK population in terms of demographics and medical conditions. The Read classification system is used to code specific diagnoses, ${ }^{5}$ whereas a dictionary based on the Multilex classification system is used to code drugs. ${ }^{6}$ The validity of THIN for use in clinical and epidemiological research studies has been demonstrated in a previous study. ${ }^{7}$

\section{Study design and cohort definition}

Eligible participants included individuals aged 50 years or older ${ }^{8}$ with $\geq 1$ year of continuous enrolment with the general practice from January 2000 through December 2017. We conducted three matched cohort studies to compare the risk of VTE among individuals with clinically diagnosed incident knee, hip or hand OA only, respectively, compared with up to five individuals without OA (ie, without any site OA), matched by same age, sex, calendar year of entry (ie, the index date or date of incident $\mathrm{OA}$ diagnoses) and body mass index (BMI) $\left( \pm 0.5 \mathrm{~kg} / \mathrm{m}^{2}\right)$. Individuals with $\mathrm{OA}$ that occurred at multiple sites (eg, knee, hip and hand), or without indicating specific site of OA, or individuals without BMI data were not eligible. We used Read codes to define knee, hip and hand OA (online supplementary table S1) according to previous studies using THIN database. ${ }^{9-12}$ This approach has been preferred in validation studies, as opposed to other approaches, such as medical visits, referrals or prescription records. ${ }^{13-15}$ Individuals were excluded from the analysis if they had knee or hip replacement prior to the index date (date of incident OA diagnosis), had neither GP visit nor specialist referral within 1 year prior to the index date, or had a history of VTE prior to the index date. Individuals who had been prescribed non-steroidal anti-inflammatory drugs, paracetamol or opioids within 1 year prior to the index date were also excluded as the potential prevalent OA cases may introduce selection bias. ${ }^{16}$ We conducted two additional matched cohort studies to compare the risk of VTE in the incident knee or hip OA cohort with that in the incident hand OA cohort.

\section{Assessment of outcomes}

The primary outcome was VTE (the combined endpoint of PE and DVT), with secondary outcomes of PE and DVT, separately. An individual was considered to have developed the outcome of interest if he or she had a recorded Read code of PE or DVT (online supplementary table S1) and received anticoagulant treatment. ${ }^{17}$ In addition, since VTE is potentially fatal and some individuals might have died before receiving anticoagulation, we also included individuals with a recorded code of PE or DVT but without a prescription for anticoagulant or autopsy results if there was a fatal outcome within 1 month of the VTE diagnosis. ${ }^{18} 19$ This VTE definition has a confirmation rate of $94 \%$ in the UK Clinical Practice Research Datalink, ${ }^{17}$ a similar database to THIN. ${ }^{20}$

\section{Assessment of covariates}

Sociodemographic and anthropometric characteristics, lifestyle factors, comorbidities, as well as medication use were obtained from the database before the index date (see table 1).

\section{Assessment of potential mediator}

Because major surgery is a strong risk factor for VTE and a previous study has found that knee or hip replacement was associated with a 10-fold to 11-fold increased risk of VTE during 6 months of follow-up, but not thereafter, ${ }^{21}$ we considered knee or hip replacement a potential mediator in the causal pathways between knee or hip OA and VTE (online supplementary figure S1). We also considered other major surgeries (ie, surgeries other than knee and hip replacement) a potential mediator. The putative mediators (knee or hip replacement and other major surgeries) were assessed within 6 months prior to the development of VTE, death, disenrolment from a GP practice participating in THIN or the end of follow-up. ${ }^{21}$

\section{Statistical analysis}

We estimated that approximately 22000,12000 and 7000 individuals with incident knee, hip and hand OA, with 110 000, 60 000 and 35000 matched individuals without OA, respectively, will be identified from 2000 to 2017. Assuming the risk of incident VTE among matched individuals without OA is $1.0 \%$, with type 2 error of 0.05 , our study will have $80 \%$ power to detect a relative risk of $1.21,1.29$ and 1.39 , respectively.

We compared baseline characteristics between each incident OA cohort (knee, hip and hand) and its comparative cohort. ${ }^{22}$ Person-years of follow-up for each individual were computed as the amount of time from the index date to the date of the following events: VTE, death, disenrolment from a GP practice participating in THIN or the end of follow-up (31 December 2017), whichever occurred first. We plotted the cumulative incidence curves for VTE, PE and DVT in each cohort accounting for the competing risk of death, ${ }^{23}$ and fitted a Cox proportional hazards model to estimate HRs accounting for matched study design. In the multivariable Cox proportional hazard models, we adjusted for potential confounders (table 1). We tested the proportional hazards assumption using the Kolmogorov supremum test. ${ }^{24}$ Since some individuals without OA could develop OA during the follow-up, we conducted a sensitivity analysis by censoring their follow-up at the time when they developed OA.

We performed mediation analyses to examine the extent to which any association between knee or hip OA and VTE (total effect) was mediated through knee or hip replacement. Using marginal structural models, we estimated the natural indirect effect (the effect of knee or hip OA on the risk of VTE mediated through knee or hip replacement) and the natural direct effect (the effect of knee or hip OA on the risk of VTE not mediated through knee or hip replacement), while controlling for potential confounders. ${ }^{25}$ Additionally, we estimated the percentage of the total effect of OA on the risk of VTE that was mediated via knee or hip replacement. ${ }^{26}$ We took the same approach to estimate the mediation effect via other major surgeries.

For all analyses, missing values for smoking status and alcohol consumption were imputed using IVEware for SAS V.9.4, which is based on chained equations. ${ }^{27}$ To minimise random error, we imputed 20 data sets and then combined estimates from these data sets. ${ }^{28} 29$ Detailed information is described in online supplementary text, and the results from the corresponding complete case analyses are presented in online supplementary table S2. 
Table 1 Baseline characteristics of individuals in the incident $\mathrm{OA}$ cohorts and their matched non-OA cohorts

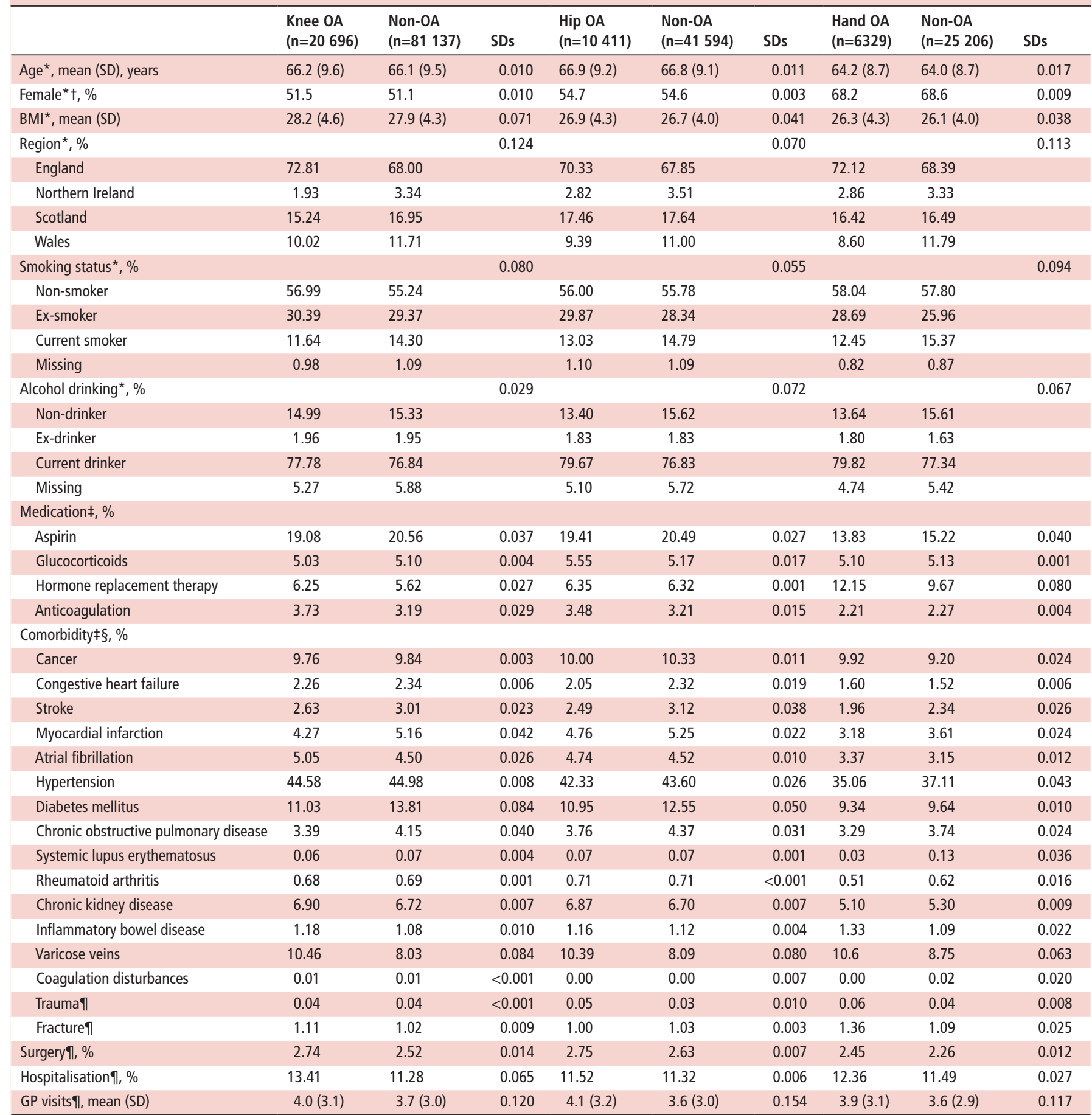

*Sociodemographic and anthropometric characteristics (age, sex, BMI and region) and lifestyle factors (smoking status and alcohol drinking) were assessed using the nearest available data prior to the index date.

†Before age, sex, entry time and BMI matching, the female ratios were $54.7 \%$ in knee OA cohort and $51.7 \%$ in its comparative non-OA cohort; $57.2 \%$ in hip $0 \mathrm{~A}$ cohort and $51.7 \%$ in its comparative non-OA cohort; and $67.2 \%$ in hand $\mathrm{OA}$ cohort and $51.7 \%$ in its comparative non-OA cohort.

$\ddagger$ Comorbidities were assessed at any time and all medication use was assessed within 1 year before the index date.

$\S$ We defined the presence of comorbidities using Read codes as recorded by GPs.

१The occurrence of trauma, fracture, surgery and hospitalisation, as well as the number of GP visits, were ascertained in the year prior to the index date.

$\mathrm{BMI}$, body mass index; GP, general practitioner; OA, osteoarthritis; SDs, standardised differences.

\section{RESULTS}

The flow charts depicting the selection process of individuals are shown in online supplementary figures S2-4. Overall, the characteristics of the knee, hip and hand OA cohorts were similar to their matched non-OA cohorts, respectively, with standardised differences $\leq 0.1$ (table 1$).{ }^{30}$
The risk of VTE was higher in the knee OA cohort than in its matched non-OA cohort (figure 1A). As shown in table 2, 327 new cases of VTE occurred in the knee OA cohort (2.7 per 1000 person-years) and 951 cases in the non-OA cohort $(2.0$ per 1000 person-years) during the follow-up period. The rate difference (RD) of VTE between the knee OA and non-OA 


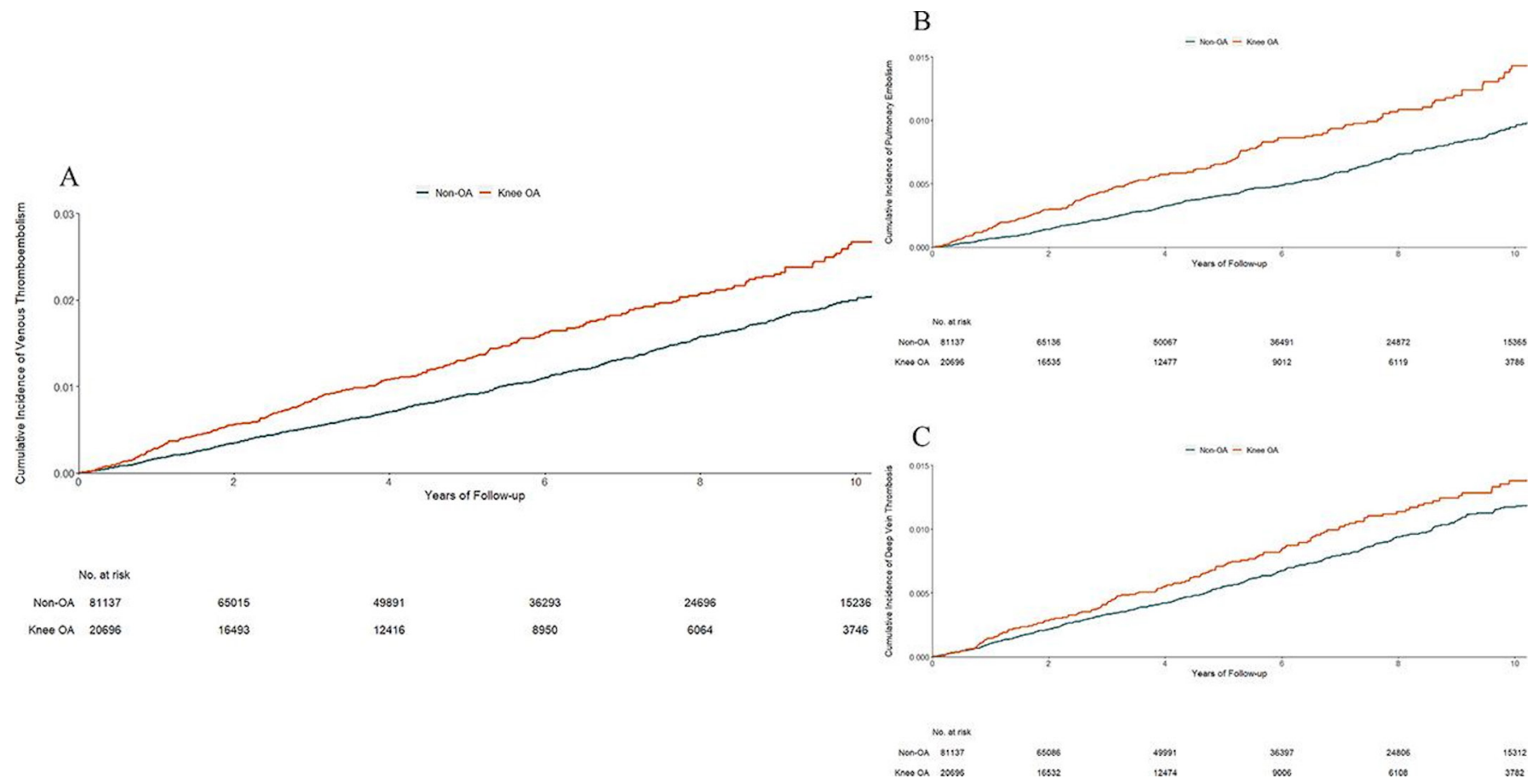

Figure 1 Cumulative incidence of venous thromboembolism (A), pulmonary embolism (B) and deep vein thrombosis (C) in 20696 individuals with incident knee $\mathrm{OA}$ as compared with 81137 individuals without $\mathrm{OA}$, matched by age, sex, entry time and BMI. BMI, body mass index; $O A$, osteoarthritis.

cohorts was 0.7 (95\% CI 0.4 to 1.0$)$ per 1000 person-years and the multivariable-adjusted HR was 1.38 (95\% CI 1.23 to 1.56) during the entire follow-up period. Since the proportional hazard assumption was violated $(\mathrm{p}<0.05)$, follow-up time was divided into $\leq 2,4,6,8$ and 10 years. The HR over 2 years was 1.60 (95\% CI 1.29 to 1.98 ), 4 years was 1.54 (95\% CI 1.32 to 1.81), 6 years was 1.49 (95\% CI 1.30 to 1.71$)$, 8 years was 1.41 (95\% CI 1.24 to 1.61 ) and 10 years was 1.41 (95\% CI 1.25 to 1.59). The risk of knee replacement was 10 -fold greater among the knee OA cohort than its matched non-OA cohort $(13.3 \%$ vs $1.3 \%$ ), and the risk of VTE was 13 -fold greater among those with knee replacement than those without knee replacement within 6 months prior to the occurrence of VTE, death, disenrolment or the end of follow-up (15.8\% vs $1.2 \%)$. The indirect effect (HR) of knee OA on VTE through knee replacement was 1.07 (95\% CI 1.01 to 1.15 ), explaining $24.8 \%$ of its total effect on VTE. The indirect effect (HR) of knee OA on VTE through other major surgeries was 1.01 (95\% CI 0.94 to 1.07). Individuals in the knee OA cohort also experienced a higher risk of PE (figure 1B) or DVT (figure 1C) than those in the non-OA cohort. Sensitivity and complete case analyses did not change the results materially (table 3 and online supplementary table S2).

The hip OA cohort also had a higher risk of VTE (3.3 per 1000 person-years) than its matched non-OA cohort (1.8 per 1000 person-years) (figure 2A). The RD of VTE between the hip OA and non-OA cohorts was 1.5 (95\% CI 1.0 to 2.0) per 1000 person-years. The matched and multivariable-adjusted HRs for VTE were 1.83 (95\% CI 1.57 to 2.13) and 1.83 (95\% CI 1.56 to 2.13), respectively. The risk of hip replacement was 20 -fold greater among the hip OA cohort than its matched non-OA cohort $(36.0 \%$ vs $1.8 \%)$, and the risk of VTE was 12 -fold greater among those with hip replacement than those without hip replacement within 6 months prior to the occurrence of VTE, death, disenrolment or the end of follow-up (14.9\% vs 1.2\%). The indirect effect through hip replacement yielded an
HR of 1.14 (95\% CI 1.04 to 1.25 ), explaining $28.1 \%$ of its total effect on VTE. The indirect effect (HR) of hip OA on VTE through other major surgeries was 1.01 (95\% CI 0.92 to 1.10). Compared with the non-OA cohort, the hip OA cohort was also at a higher risk of either PE (figure $2 \mathrm{~B}$ ) or DVT (figure 2C). The results from the sensitivity and complete case analyses did not change materially (table 3 and online supplementary table S2).

No statistically significant difference in the risk of VTE was observed between the hand OA cohort (1.5 per 1000 personyears) and its matched non-OA cohort (1.6 per 1000 personyears) (figure $3 \mathrm{~A}$ ). Compared with the non-OA cohort, the multivariable-adjusted HR was 0.88 (95\% CI 0.67 to 1.16 ) (table 2). The hand OA cohort did not experience a higher risk of either PE (figure $3 \mathrm{~B}$ ) or DVT (figure 3C). The results from the sensitivity and complete case analyses did not change materially (table 3 and online supplementary table S2). In addition, the risk of VTE was higher in the incident knee OA cohort (multivariable-adjusted $\mathrm{HR}=1.46,95 \% \mathrm{CI} 1.05$ to 2.02 ) and the hip OA cohort (multivariable-adjusted $\mathrm{HR}=1.87,95 \%$ CI 1.07 to 3.26 ) than that in the hand OA cohort.

\section{DISCUSSION}

Our novel findings showed that the risk of incident VTE increased approximately $40 \%$ among individuals with knee OA and $80 \%$ among individuals with hip OA compared with those without OA. An increased risk of VTE in knee or hip OA was partly mediated through knee or hip replacement.

\section{Comparison with previous studies}

To date, many studies have examined the association between OA and risk of cardiovascular events; results, however, have been inconclusive. ${ }^{31-51}$ Some studies reported that OA was associated with an increased risk of cardiovascular events, 3132394446 while others failed to confirm it. ${ }^{3437384251}$ In addition, several studies 
Table 2 Association between incident OA and risk of venous thromboembolism (primary analysis)

\begin{tabular}{|c|c|c|c|c|c|c|}
\hline & $\begin{array}{l}\text { Knee OA } \\
(n=20696)\end{array}$ & $\begin{array}{l}\text { Non- } 0 A(n=81 \\
137)\end{array}$ & $\begin{array}{l}\text { Hip OA }(n=10 \\
\text { 411) }\end{array}$ & $\begin{array}{l}\text { Non-0A }(n=41 \\
594)\end{array}$ & $\begin{array}{l}\text { Hand OA } \\
(\mathrm{n}=6329)\end{array}$ & $\begin{array}{l}\text { Non- } 0 A(n=25 \\
206)\end{array}$ \\
\hline \multicolumn{7}{|l|}{ Venous thromboembolism } \\
\hline Events (n) & 327 & 951 & 201 & 449 & 57 & 234 \\
\hline Mean follow-up (years) & 5.86 & 5.99 & 5.83 & 5.96 & 5.84 & 5.92 \\
\hline Incidence rate, per 1000 person-years & 2.7 & 2.0 & 3.3 & 1.8 & 1.5 & 1.6 \\
\hline $\mathrm{RD}(95 \% \mathrm{Cl})$, per 1000 person-years & $\begin{array}{l}0.7 \\
(0.4 \text { to } 1.0)\end{array}$ & $\begin{array}{l}0.0 \\
\text { (reference) }\end{array}$ & $\begin{array}{l}1.5 \\
(1.0 \text { to } 2.0)\end{array}$ & $\begin{array}{l}0.0 \\
\text { (reference) }\end{array}$ & $\begin{array}{l}-0.1 \\
(-0.6 \text { to } 0.4)\end{array}$ & $\begin{array}{l}0.0 \\
\text { (reference) }\end{array}$ \\
\hline $\begin{array}{l}\text { Age, sex, BMI and entry year-matched HR ( } 95 \% \\
\text { Cl) }\end{array}$ & $\begin{array}{l}1.40 \\
(1.25 \text { to } 1.57)\end{array}$ & $\begin{array}{l}1.00 \\
\text { (reference) }\end{array}$ & $\begin{array}{l}1.83 \\
\text { (1.57 to } 2.13)\end{array}$ & $\begin{array}{l}1.00 \\
\text { (reference) }\end{array}$ & $\begin{array}{l}0.94 \\
(0.71 \text { to } 1.23)\end{array}$ & $\begin{array}{l}1.00 \\
\text { (reference) }\end{array}$ \\
\hline Multivariable-adjusted HR $(95 \% \mathrm{Cl})^{*}$ & $\begin{array}{l}1.38 \\
\text { (1.23 to } 1.56)\end{array}$ & $\begin{array}{l}1.00 \\
\text { (reference) }\end{array}$ & $\begin{array}{l}1.83 \\
\text { (1.56 to } 2.13)\end{array}$ & $\begin{array}{l}1.00 \\
\text { (reference) }\end{array}$ & $\begin{array}{l}0.88 \\
(0.67 \text { to } 1.16)\end{array}$ & $\begin{array}{l}1.00 \\
\text { (reference) }\end{array}$ \\
\hline \multicolumn{7}{|l|}{ Pulmonary embolism } \\
\hline Events (n) & 172 & 445 & 101 & 229 & 25 & 113 \\
\hline Mean follow-up (years) & 5.89 & 6.02 & 5.88 & 5.98 & 5.86 & 5.94 \\
\hline Incidence rate, per 1000 person-years & 1.4 & 0.9 & 1.6 & 0.9 & 0.7 & 0.8 \\
\hline $\mathrm{RD}(95 \% \mathrm{Cl})$, per 1000 person-years & $\begin{array}{l}0.5 \\
(0.3 \text { to } 0.7)\end{array}$ & $\begin{array}{l}0.0 \\
\text { (reference) }\end{array}$ & $\begin{array}{l}0.7 \\
(0.4 \text { to } 1.0)\end{array}$ & $\begin{array}{l}0.0 \\
\text { (reference) }\end{array}$ & $\begin{array}{l}-0.1 \\
(-0.4 \text { to } 0.2)\end{array}$ & $\begin{array}{l}0.0 \\
\text { (reference) }\end{array}$ \\
\hline $\begin{array}{l}\text { Age, sex, BMI and entry year-matched HR ( } 95 \% \\
\text { Cl) }\end{array}$ & $\begin{array}{l}1.62 \\
(1.39 \text { to } 1.90)\end{array}$ & $\begin{array}{l}1.00 \\
\text { (reference) }\end{array}$ & $\begin{array}{l}1.81 \\
\text { (1.46 to } 2.24)\end{array}$ & $\begin{array}{l}1.00 \\
\text { (reference) }\end{array}$ & $\begin{array}{l}0.88 \\
\text { (0.58 to } 1.32)\end{array}$ & $\begin{array}{l}1.00 \\
\text { (reference) }\end{array}$ \\
\hline Multivariable-adjusted HR $(95 \% \mathrm{Cl})^{*}$ & $\begin{array}{l}1.65 \\
\text { (1.40 to } 1.95)\end{array}$ & $\begin{array}{l}1.00 \\
\text { (reference) }\end{array}$ & $\begin{array}{l}1.92 \\
\text { (1.53 to } 2.42)\end{array}$ & $\begin{array}{l}1.00 \\
\text { (reference) }\end{array}$ & $\begin{array}{l}0.86 \\
(0.56 \text { to } 1.32)\end{array}$ & $\begin{array}{l}1.00 \\
\text { (reference) }\end{array}$ \\
\hline \multicolumn{7}{|l|}{ Deep vein thrombosis } \\
\hline Events (n) & 174 & 563 & 115 & 245 & 36 & 127 \\
\hline Mean follow-up (years) & 5.89 & 6.01 & 5.86 & 5.97 & 5.85 & 5.94 \\
\hline Incidence rate, per 1000 person-years & 1.4 & 1.1 & 1.9 & 1.0 & 1.0 & 0.9 \\
\hline RD $(95 \% \mathrm{Cl})$, per 1000 person-years & $\begin{array}{l}0.3 \\
(0.1 \text { to } 0.5)\end{array}$ & $\begin{array}{l}0.0 \\
\text { (reference) }\end{array}$ & $\begin{array}{l}0.9 \\
(0.5 \text { to } 1.3)\end{array}$ & $\begin{array}{l}0.0 \\
\text { (reference) }\end{array}$ & $\begin{array}{l}0.1 \\
(-0.3 \text { to } 0.5)\end{array}$ & $\begin{array}{l}0.0 \\
\text { (reference) }\end{array}$ \\
\hline $\begin{array}{l}\text { Age, sex, BMl and entry year-matched HR ( } 95 \% \\
\text { Cl) }\end{array}$ & $\begin{array}{l}1.24 \\
(1.06 \text { to } 1.45)\end{array}$ & $\begin{array}{l}1.00 \\
\text { (reference) }\end{array}$ & $\begin{array}{l}1.94 \\
\text { (1.59 to } 2.38)\end{array}$ & $\begin{array}{l}1.00 \\
\text { (reference) }\end{array}$ & $\begin{array}{l}1.10 \\
(0.77 \text { to } 1.55)\end{array}$ & $\begin{array}{l}1.00 \\
\text { (reference) }\end{array}$ \\
\hline Multivariable-adjusted HR $(95 \% \mathrm{Cl})^{*}$ & $\begin{array}{l}1.21 \\
\text { (1.03 to } 1.42)\end{array}$ & $\begin{array}{l}1.00 \\
\text { (reference) }\end{array}$ & $\begin{array}{l}1.87 \\
\text { (1.52 to } 2.31)\end{array}$ & $\begin{array}{l}1.00 \\
\text { (reference) }\end{array}$ & $\begin{array}{l}1.01 \\
(0.70 \text { to } 1.44)\end{array}$ & $\begin{array}{l}1.00 \\
\text { (reference) }\end{array}$ \\
\hline
\end{tabular}

*In addition to the matching variables, multivariable models were adjusted for region, smoking status (ie, non-smokers, ex-smokers and current smokers), alcohol drinking (ie, non-drinkers, ex-drinkers and current drinkers), number of GP visits, comorbidities, medication use, trauma, fracture, surgery and hospitalisation prior to the index date.

$\mathrm{BMI}$, body mass index; GP, general practitioner; $\mathrm{n}$, number; $\mathrm{OA}$, osteoarthritis; RD, rate difference.

found that knee or hip OA, but not hand OA, was associated with an increased risk of cardiovascular events, and immobility may be a potential explanation for such site-specific difference. ${ }^{40} 4147$ Indeed, results from the Wuchuan Osteoarthritis Study showed that the relation of symptomatic knee OA to allcause mortality was almost entirely $(96.8 \%)$ mediated through its effect on walking disability. ${ }^{52}$ Results from the Osteoarthritis Initiative showed that $22.4 \%$ of the effect of symptomatic knee OA on all-cause mortality was mediated through disability in physical function and $26.5 \%$ was mediated through impaired physical component summary scores of quality of life. ${ }^{53} \mathrm{~A}$ similar finding was also reported in the Study of Osteoporotic Fractures, and the percentage of the total effect of hip OA on all-cause mortality mediated by physical function was $42.9 \% .^{32}$ A few studies also showed that hand OA may increase the risk of cardiovascular events, and OA-related systemic inflammation may be the potential explanation. ${ }^{35} 3649$

\section{Possible explanations}

Several explanations may account for our findings. First, immobilisation or prolonged physical inactivity could substantially increase the risk of VTE through inducing muscular and diaphragm dysfunction, venous stasis, and a hypercoagulability state. ${ }^{354}$ Thus, OA-related immobility may play a key role in the development of VTE. Second, knee or hip replacement is associated with a substantially increased risk of VTE. ${ }^{21}$ In the current study, $24.8 \%$ of the effect of knee OA on the risk of VTE was mediated through knee replacement and $28.1 \%$ of the hip OA effect on VTE was mediated through hip replacement, suggesting knee and hip replacement surgery indeed played an important role in the association between knee or hip OA and risk of VTE.

\section{Strengths and limitations}

First, we matched individuals with $\mathrm{OA}$ with individuals without OA on age, sex, BMI and entry time, and adjusted for major potential confounders for VTE in the analyses. The matched and multivariable-adjusted effect estimates were consistent, suggesting that residual confounders should not greatly alter the observed associations. Second, we compared the risk of VTE among the incident instead of prevalent OA cases with those of individuals without OA, to minimise potential selection bias. ${ }^{16}$ Third, no apparent mediation effect was observed through other major surgeries except knee and hip replacement, indicating that the knee or hip OA cohort was comparable with its matched non-OA cohort in potential confounders. Finally, immobility and surgery, including knee or hip replacement, are the two major risk factors for VTE ${ }^{321}$ lending credibility to our observations that the increased risk of VTE was only among patients with knee or hip OA, but not hand OA.

Limitations of our study should be acknowledged. First, we used Read codes to define knee, hip and hand OA, and it 


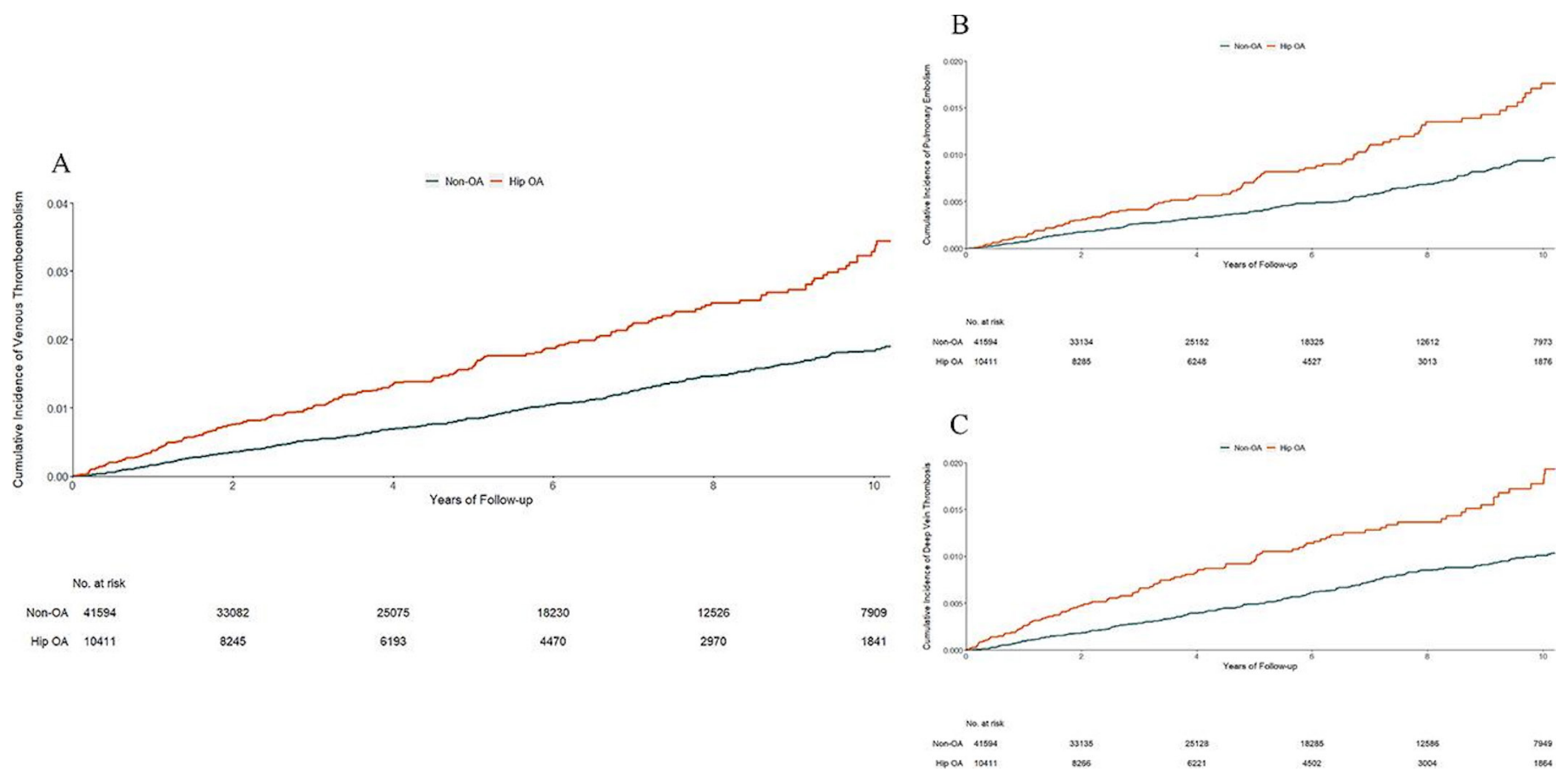

Figure 2 Cumulative incidence of venous thromboembolism (A), pulmonary embolism (B) and deep vein thrombosis (C) in 10411 individuals with incident hip OA as compared with 41594 individuals without OA, matched by age, sex, entry time and BMI. BMI, body mass index; OA, osteoarthritis.

is possible that some individuals with mild symptomatic OA may not seek care from their GPs and could be included in the comparison cohort. Such misclassification may bias our effect estimates in either way (ie, either towards or away from the null). However, when we censored the follow-up time for individuals who were diagnosed with OA during the follow-up, the results did not change materially. Second, the residual confounding still cannot be ruled out, although we used several approaches to control for potential confounding bias. For example, in THIN database, severity for most diseases was not collected. If severity of other comorbidities in the OA cohort differs from that in the non-OA cohort, this may lead to potential bias. Third, excluding patients with OA who had no BMI information or who cannot find matched individuals without OA may limit generalisability of our findings. Fourth, we cannot directly examine whether the association between OA and risk of VTE was mediated through
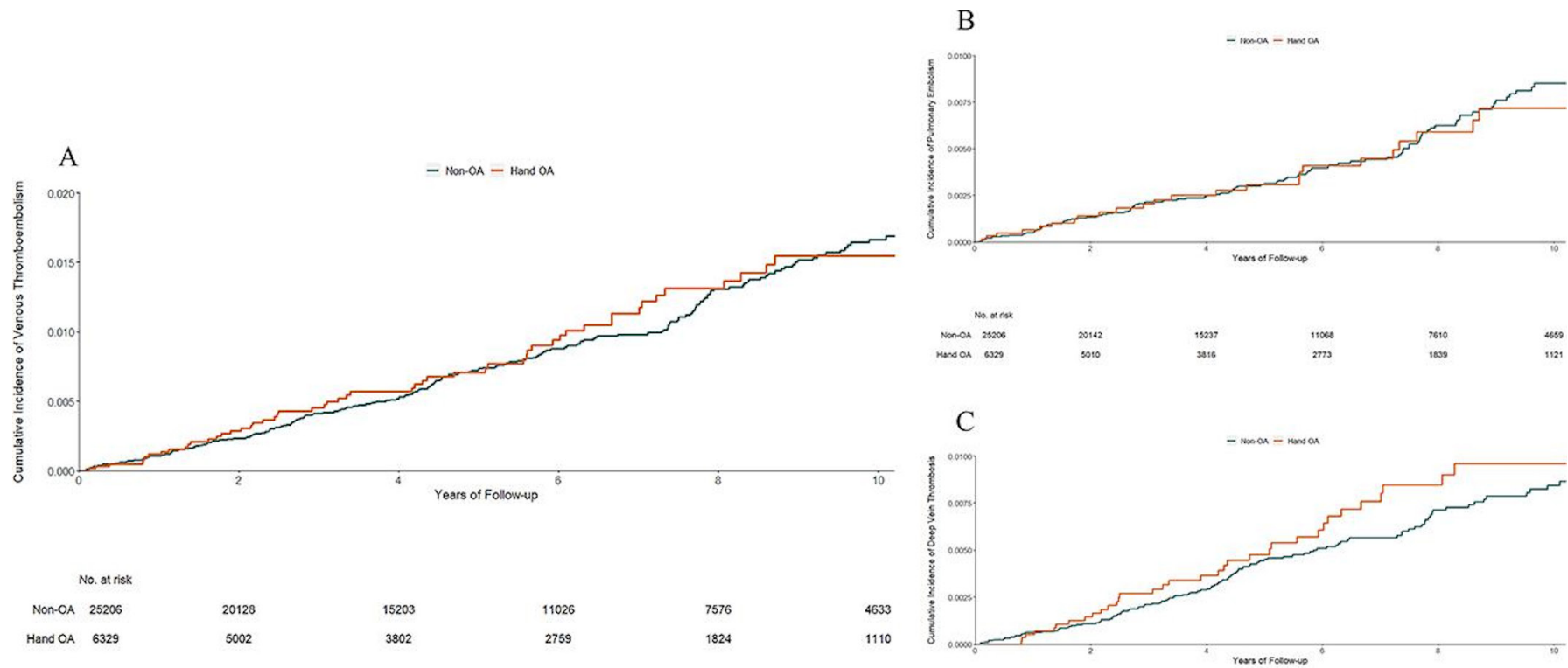

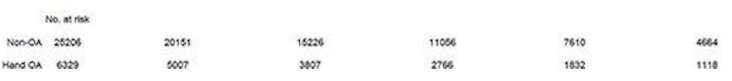

Figure 3 Cumulative incidence of venous thromboembolism (A), pulmonary embolism (B) and deep vein thrombosis (C) in 6329 individuals with incident hand $\mathrm{OA}$ as compared with 25206 individuals without $\mathrm{OA}$, matched by age, sex, entry time and BMI. BMI, body mass index; $\mathrm{OA}$, osteoarthritis. 
Table 3 Association between incident $\mathrm{OA}$ and risk of venous thromboembolism (sensitivity analysis)

\begin{tabular}{|c|c|c|c|c|c|c|}
\hline & $\begin{array}{l}\text { Knee OA }(n=20 \\
696)\end{array}$ & $\begin{array}{l}\text { Non-OA }(n=81 \\
137)\end{array}$ & $\begin{array}{l}\text { Hip OA }(n=10 \\
411)\end{array}$ & $\begin{array}{l}\text { Non-OA }(n=41 \\
594)\end{array}$ & $\begin{array}{l}\text { Hand } O A \\
(n=6329) \\
\end{array}$ & $\begin{array}{l}\text { Non-OA } \\
(n=25 \text { 206) }\end{array}$ \\
\hline \multicolumn{7}{|l|}{ Venous thromboembolism } \\
\hline Events (n) & 327 & 834 & 201 & 393 & 57 & 211 \\
\hline Mean follow-up (years) & 5.86 & 5.50 & 5.83 & 5.50 & 5.84 & 5.50 \\
\hline Incidence rate, per 1000 person-years & 2.7 & 1.9 & 3.3 & 1.7 & 1.5 & 1.5 \\
\hline RD $(95 \% \mathrm{Cl})$, per 1000 person-years & $\begin{array}{l}0.8 \\
\text { (0.5 to } 1.1)\end{array}$ & $\begin{array}{l}0.0 \\
\text { (reference) }\end{array}$ & $\begin{array}{l}1.6 \\
\text { (1.1 to } 2.1 \text { ) }\end{array}$ & $\begin{array}{l}0.0 \\
\text { (reference) }\end{array}$ & $\begin{array}{l}0.0 \\
(-0.5 \text { to } 0.5)\end{array}$ & $\begin{array}{l}0.0 \\
\text { (reference) }\end{array}$ \\
\hline Age, sex, BMI and entry year-matched $\mathrm{HR}(95 \% \mathrm{Cl})$ & $\begin{array}{l}1.47 \\
\text { (1.31 to } 1.66)\end{array}$ & $\begin{array}{l}1.00 \\
\text { (reference) }\end{array}$ & $\begin{array}{l}1.90 \\
\text { (1.63 to } 2.21)\end{array}$ & $\begin{array}{l}1.00 \\
\text { (reference) }\end{array}$ & $\begin{array}{l}0.97 \\
\text { (0.74 to } 1.28)\end{array}$ & $\begin{array}{l}1.00 \\
\text { (reference) }\end{array}$ \\
\hline Multivariable-adjusted HR $(95 \% \mathrm{Cl})^{*}$ & $\begin{array}{l}1.45 \\
\text { (1.29 to } 1.64)\end{array}$ & $\begin{array}{l}1.00 \\
\text { (reference) }\end{array}$ & $\begin{array}{l}1.87 \\
\text { (1.60 to } 2.20)\end{array}$ & $\begin{array}{l}1.00 \\
\text { (reference) }\end{array}$ & $\begin{array}{l}0.91 \\
(0.70 \text { to } 1.20)\end{array}$ & $\begin{array}{l}1.00 \\
\text { (reference) }\end{array}$ \\
\hline \multicolumn{7}{|l|}{ Pulmonary embolism } \\
\hline Events (n) & 172 & 390 & 101 & 196 & 25 & 100 \\
\hline Mean follow-up (years) & 5.89 & 5.52 & 5.88 & 5.52 & 5.86 & 5.51 \\
\hline Incidence rate, per 1000 person-years & 1.4 & 0.9 & 1.7 & 0.9 & 0.7 & 0.7 \\
\hline RD $(95 \% \mathrm{Cl})$, per 1000 person-years & $\begin{array}{l}0.5 \\
(0.3 \text { to } 0.7)\end{array}$ & $\begin{array}{l}0.0 \\
\text { (reference) }\end{array}$ & $\begin{array}{l}0.8 \\
(0.5 \text { to } 1.1)\end{array}$ & $\begin{array}{l}0.0 \\
\text { (reference) }\end{array}$ & $\begin{array}{l}0.0 \\
(-0.3 \text { to } 0.3)\end{array}$ & $\begin{array}{l}0.0 \\
\text { (reference) }\end{array}$ \\
\hline Age, sex, BMI and entry year-matched $\mathrm{HR}(95 \% \mathrm{Cl})$ & $\begin{array}{l}1.71 \\
\text { (1.45 to } 2.01)\end{array}$ & $\begin{array}{l}1.00 \\
\text { (reference) }\end{array}$ & $\begin{array}{l}1.94 \\
\text { (1.57 to } 2.41)\end{array}$ & $\begin{array}{l}1.00 \\
\text { (reference) }\end{array}$ & $\begin{array}{l}0.89 \\
\text { (0.59 to } 1.35 \text { ) }\end{array}$ & $\begin{array}{l}1.00 \\
\text { (reference) }\end{array}$ \\
\hline Multivariable-adjusted $\mathrm{HR}(95 \% \mathrm{Cl})^{*}$ & $\begin{array}{l}1.73 \\
\text { (1.47 to } 2.05)\end{array}$ & $\begin{array}{l}1.00 \\
\text { (reference) }\end{array}$ & $\begin{array}{l}2.08 \\
(1.65 \text { to } 2.63)\end{array}$ & $\begin{array}{l}1.00 \\
\text { (reference) }\end{array}$ & $\begin{array}{l}0.87 \\
\text { (0.56 to } 1.34 \text { ) }\end{array}$ & $\begin{array}{l}1.00 \\
\text { (reference) }\end{array}$ \\
\hline \multicolumn{7}{|l|}{ Deep vein thrombosis } \\
\hline Events (n) & 174 & 491 & 115 & 219 & 36 & 117 \\
\hline Mean follow-up (years) & 5.89 & 5.51 & 5.86 & 5.51 & 5.85 & 5.51 \\
\hline Incidence rate, per 1000 person-years & 1.4 & 1.1 & 1.9 & 1.0 & 1.0 & 0.8 \\
\hline RD $(95 \% \mathrm{Cl})$, per 1000 person-years & $\begin{array}{l}0.3 \\
\text { (0.1 to } 0.5 \text { ) }\end{array}$ & $\begin{array}{l}0.0 \\
\text { (reference) }\end{array}$ & $\begin{array}{l}0.9 \\
(0.5 \text { to } 1.3)\end{array}$ & $\begin{array}{l}0.0 \\
\text { (reference) }\end{array}$ & $\begin{array}{l}0.2 \\
(-0.2 \text { to } 0.6)\end{array}$ & $\begin{array}{l}0.0 \\
\text { (reference) }\end{array}$ \\
\hline Age, sex, BMI and entry year-matched $\mathrm{HR}(95 \% \mathrm{Cl})$ & $\begin{array}{l}1.31 \\
\text { (1.12 to } 1.53)\end{array}$ & $\begin{array}{l}1.00 \\
\text { (reference) }\end{array}$ & $\begin{array}{l}1.93 \\
\text { (1.57 to } 2.38)\end{array}$ & $\begin{array}{l}1.00 \\
\text { (reference) }\end{array}$ & $\begin{array}{l}1.15 \\
\text { (0.82 to } 1.61)\end{array}$ & $\begin{array}{l}1.00 \\
\text { (reference) }\end{array}$ \\
\hline Multivariable-adjusted $\mathrm{HR}(95 \% \mathrm{Cl})^{*}$ & $\begin{array}{l}1.28 \\
\text { (1.09 to } 1.50)\end{array}$ & $\begin{array}{l}1.00 \\
\text { (reference) }\end{array}$ & $\begin{array}{l}1.87 \\
\text { (1.51 to } 2.31)\end{array}$ & $\begin{array}{l}1.00 \\
\text { (reference) }\end{array}$ & $\begin{array}{l}1.07 \\
\text { (0.76 to } 1.52)\end{array}$ & $\begin{array}{l}1.00 \\
\text { (reference) }\end{array}$ \\
\hline
\end{tabular}

*In addition to the matching variables, multivariable models were adjusted for region, smoking status (ie, non-smokers, ex-smokers and current smokers), alcohol drinking (ie, non-drinkers, ex-drinkers and current drinkers), number of GP visits, comorbidities, medication use, trauma, fracture, surgery and hospitalisation prior to the index date. $\mathrm{BMI}$, body mass index; $\mathrm{n}$, number; $\mathrm{OA}$, osteoarthritis; $\mathrm{RD}$, rate difference.

immobility owing to lack of detailed information of immobility and physical activity level in THIN.

\section{Clinical implications}

VTE is a condition that can result in substantial morbidity and mortality; however, to date, the cause is still unknown in a third to a half of VTE cases. ${ }^{55}$ Our study showed that the incidence rates of VTE among patients with knee (2.7 per 1000 personyears) or hip (3.3 per 1000 person-years) OA were similar to that among patients with rheumatoid arthritis (3.3 per 1000 person-years) from the THIN database. ${ }^{18}$ Although the RD of VTE between the knee or hip OA and non-OA cohorts was relatively small (0.7 or 1.5 per 1000 person-years), the present study, if confirmed by other studies, will help identify a large proportion of high-risk population for VTE given that knee and hip OA are much more common than rheumatoid arthritis and have a growing prevalence due to the global ageing population and obesity epidemic. ${ }^{1}$

Clinicians managing patients with knee or hip OA, especially those with movement limitations, could then have a high index of suspicion for VTE, particularly in the presence of non-specific symptoms and signs. Our findings also help shed light on potential mechanisms linking OA to VTE and may guide development of evidence-based preventive strategies for VTE. For example, we postulate that immobility due to knee or hip OA is likely to play an important role linking knee and hip OA with an elevated risk of VTE; thus, strategies aimed at encouraging patients with knee or hip OA to actively participate in physical activities seem justified. ${ }^{56-61}$ In addition, as joint replacement surgery, a clinically relevant and cost-effective treatment for end-stage OA, continuously grows worldwide, more efforts (eg, early mobilisation following surgery) are still needed to further reduce the risk of VTE after surgery. ${ }^{62} 63$

\section{CONCLUSION}

Our study provides the first evidence that knee or hip OA, but not hand OA, was associated with an increased risk of VTE, and such an association was partially mediated through knee or hip replacement. Since OA is a prevalent disease and VTE is a serious condition, further studies are needed to confirm our findings and to understand biological mechanisms, so that appropriate prevention, monitoring and treatment strategies can be developed to reduce the disease burden in patients with knee or hip OA.

\section{Author affiliations}

'Department of Orthopaedics, Xiangya Hospital, Central South University, Changsha, China 
${ }^{2}$ Division of Rheumatology, Allergy, and Immunology, Department of Medicine, Massachusetts General Hospital, Harvard Medical School, Boston, Massachusetts, USA

${ }^{3}$ The Mongan Institute, Massachusetts General Hospital, Harvard Medical School, Boston, Massachusetts, USA

${ }^{4}$ Hunan Key Laboratory of Joint Degeneration and Injury, Xiangya Hospital, Central South University, Changsha, China

${ }^{5}$ National Clinical Research Center of Geriatric Disorders, Xiangya Hospital, Central South University, Changsha, China

${ }^{6}$ Centre for Health, Exercise and Sports Medicine, The University of Melbourne, Melbourne, Victoria, Australia

${ }^{7}$ Department of Biostatistics and Epidemiology, University of North Texas Health Science Center, School of Public Health, Fort Worth, Texas, USA

${ }^{8}$ Arthritis Research Centre, Richmond, British Columbia, Canada

${ }^{9}$ Health Management Center, Xiangya Hospital, Central South University, Changsha, China

Contributors YZ and GL had full access to all of the data in the study and take responsibility for the integrity of the data and the accuracy of the data analysis. GL and YZ are joint corresponding authors. All authors have read, provided critical feedback on intellectual content and approved the final manuscript. Concept and design: GL, YZ, CZ. Acquisition, analysis or interpretation of data: all authors. Drafting of the manuscript: $C Z, G L, Y Z$. Critical revision of the manuscript for important intellectual content: all authors. Statistical analysis: ZY, NL, JW, YZ. Obtained funding: $C Z, K B$, JW, GL. Administrative, technical or material support: CZ, GL, YZ. Supervision: $G L, Y Z$.

Funding This work was supported by the National Natural Science Foundation of China $(81772413,81702207,81702206,81930071)$, the National Health and Medical Research Council Principal Research Fellowship, the National Key Research and Development Project (2018YFB1105705), and the Key Research and Development Program of Hunan Province (2018SK2070, 2018SK2071)

Competing interests None declared.

Patient and public involvement Patients and/or the public were not involved in the design, or conduct, or reporting, or dissemination plans of this research.

Patient consent for publication Not required.

Ethics approval This study received approval from the medical ethical committee at Xiangya Hospital, with waiver of informed consent. This study was approved by the THIN Scientific Review Committee (20SRC003). THIN is a registered trademark of Cegedim SA in the UK and other countries. Reference made to the THIN database is intended to be descriptive of the data asset licensed by IQVIA. This work uses de-identified data provided by patients as part of their routine primary care.

Provenance and peer review Not commissioned; externally peer reviewed.

Data availability statement No data are available. While we are unable to share the data sets, code lists are available on request.

Open access This is an open access article distributed in accordance with the Creative Commons Attribution Non Commercial (CC BY-NC 4.0) license, which permits others to distribute, remix, adapt, build upon this work non-commercially, and license their derivative works on different terms, provided the original work is properly cited, appropriate credit is given, any changes made indicated, and the use is non-commercial. See: http://creativecommons.org/licenses/by-nc/4.0/.

\section{ORCID iDs}

Guanghua Lei http://orcid.org/0000-0003-2987-138X

Yuqing Zhang http://orcid.org/0000-0001-7638-0888

\section{REFERENCES}

1 Hunter DJ, Bierma-Zeinstra S. Osteoarthritis. Lancet 2019:393:1745-59.

2 Brooks PM. Impact of osteoarthritis on individuals and society: how much disability? social consequences and health economic implications. Curr Opin Rheumatol 2002;14:573-7.

3 Di Nisio M, van Es N, Büller HR. Deep vein thrombosis and pulmonary embolism. Lancet 2016;388:3060-73.

4 Tritschler T, Kraaijpoel N, Le Gal G, et al. Venous thromboembolism: advances in diagnosis and treatment. JAMA 2018;320:1583-94.

5 Chisholm J. The read clinical classification. BMJ 1990;300:1092.

6 First Databank. Multilex. Available: http://www.folbhealth.co.uk/solutions/multilex/ [Accessed 8 Nov 2017].

7 Lewis JD, Schinnar R, Bilker WB, et al. Validation studies of the health improvement network (THIN) database for pharmacoepidemiology research. Pharmacoepidemiol Drug Saf 2007;16:393-401.

8 Heit JA. Epidemiology of venous thromboembolism. Nat Rev Cardiol 2015;12:464-74.

9 Zeng C, Dubreuil M, LaRochelle MR, et al. Association of tramadol with all-cause mortality among patients with osteoarthritis. JAMA 2019;321:969-82.
10 Dubreuil M, Louie-Gao Q, Peloquin CE, et al. Risk of myocardial infarction with use of selected non-steroidal anti-inflammatory drugs in patients with spondyloarthritis and osteoarthritis. Ann Rheum Dis 2018;77:1137-42.

11 Neogi T, Li S, Peloquin C, et al. Effect of bisphosphonates on knee replacement surgery. Ann Rheum Dis 2018;77:92-7.

12 Misra D, Lu N, Felson D, et al. Does knee replacement surgery for osteoarthritis improve survival? the jury is still out. Ann Rheum Dis 2017;76:140-6.

13 Lix L, Yogendran M, Burchill C. Defining and validating chronic diseases: an administrative data approach, 2006. Available: http://www.umanitoba.ca/centres/ mchp/reports.htm [Accessed 29 Sept 2019].

14 Lix L, Yogendran M, Mann J. Defining and validating chronic diseases: an administrative data approach. An update with ICD-10-CA, 2008. Available: https:// www.researchgate.net/publication/242284353 [Accessed 29 Sept 2019].

15 Prieto-Alhambra D, Judge A, Javaid MK, et al. Incidence and risk factors for clinically diagnosed knee, hip and hand osteoarthritis: influences of age, gender and osteoarthritis affecting other joints. Ann Rheum Dis 2014;73:1659-64.

16 Choi HK, Nguyen U-S, Niu J, et al. Selection bias in rheumatic disease research. Nat Rev Rheumatol 2014;10:403-12.

17 Huerta C, Johansson S, Wallander M-A, et al. Risk factors and short-term mortality of venous thromboembolism diagnosed in the primary care setting in the United Kingdom. Arch Intern Med 2007;167:935-43.

18 Choi HK, Rho Y-H, Zhu Y, et al. The risk of pulmonary embolism and deep vein thrombosis in rheumatoid arthritis: a UK population-based outpatient cohort study. Ann Rheum Dis 2013:72:1182-7.

19 Ogdie A, Kay McGill N, Shin DB, et al. Risk of venous thromboembolism in patients with psoriatic arthritis, psoriasis and rheumatoid arthritis: a general population-based cohort study. Eur Heart J 2018;39:3608-14.

20 Carbonari DM, Saine ME, Newcomb CW, et al. Use of demographic and pharmacy data to identify patients included within both the Clinical Practice Research Datalink (CPRD) and The Health Improvement Network (THIN). Pharmacoepidemiol Drug Saf 2015;24:999-1003.

21 Lu N, Misra D, Neogi T, et al. Total joint arthroplasty and the risk of myocardial infarction: a general population, propensity score-matched cohort study. Arthritis Rheumatol 2015;67:2771-9.

22 Mamdani M, Sykora K, Li P, et al. Reader's guide to critical appraisal of cohort studies: 2. assessing potential for confounding. BMJ 2005;330:960-2.

23 Gooley TA, Leisenring W, Crowley J, et al. Estimation of failure probabilities in the presence of competing risks: new representations of old estimators. Stat Med 1999:18:695-706

24 Lin DY, Wei LJ, Ying Z. Checking the COX model with cumulative sums of martingalebased residuals. Biometrika 1993:80:557-72.

25 Lange T, Vansteelandt S, Bekaert M. A simple unified approach for estimating natural direct and indirect effects. Am J Epidemiol 2012;176:190-5.

26 VanderWeele TJ. Mediation analysis: a practitioner's guide. Annu Rev Public Health 2016;37:17-32.

27 van Buuren S. Flexible imputation of missing data. 2nd Edition. Boca Raton: Chapman \& Hall/CRC, 2018

28 Rubin DB. Multiple imputation for nonresponse in surveys. New York: J Wiley, 1987.

29 Sterne JAC, White IR, Carlin JB, et al. Multiple imputation for missing data in epidemiological and clinical research: potential and pitfalls. BMJ 2009;338:b2393.

30 Franklin JM, Rassen JA, Ackermann D, et al. Metrics for covariate balance in cohort studies of causal effects. Stat Med 2014:33:1685-99.

31 Atiquzzaman M, Karim ME, Kopec J, et al. Role of nonsteroidal antiinflammatory drugs in the association between osteoarthritis and cardiovascular diseases: a longitudinal study. Arthritis Rheumatol 2019;71:1835-43.

32 Barbour KE, Lui L-Y, Nevitt MC, et al. Hip osteoarthritis and the risk of all-cause and disease-specific mortality in older women: a population-based cohort study. Arthritis Rheumatol 2015;67:1798-805.

33 Cleveland RJ, Alvarez C, Schwartz TA, et al. The impact of painful knee osteoarthritis on mortality: a community-based cohort study with over 24 years of follow-up. Osteoarthritis Cartilage 2019;27:593-602.

34 Corsi M, Alvarez C, Callahan LF, et al. Contributions of symptomatic osteoarthritis and physical function to incident cardiovascular disease. BMC Musculoskelet Disord 2018;19:393.

35 Haara MM, Manninen $\mathrm{P}$, Kröger $\mathrm{H}$, et al. Osteoarthritis of finger joints in Finns aged 30 or over: prevalence, determinants, and association with mortality. Ann Rheum Dis 2003;62:151-8.

36 Haugen IK, Ramachandran VS, Misra D, et al. Hand osteoarthritis in relation to mortality and incidence of cardiovascular disease: data from the Framingham heart study. Ann Rheum Dis 2015:74:74-81.

37 Hoeven TA, Leening MJG, Bindels PJ, et al. Disability and not osteoarthritis predicts cardiovascular disease: a prospective population-based cohort study. Ann Rheum Dis 2015;74:752-6.

38 Holbrook TL, Wingard DL, Barrett-Connor E. Self-Reported arthritis among men and women in an adult community. J Community Health 1990;15:195-208.

39 Hsu P-S, Lin H-H, Li C-R, et al. Increased risk of stroke in patients with osteoarthritis: a population-based cohort study. Osteoarthritis Cartilage 2017;25:1026-31 
40 Kendzerska T, Jüni P, King LK, et al. The longitudinal relationship between hand, hip and knee osteoarthritis and cardiovascular events: a population-based cohort study. Osteoarthritis Cartilage 2017;25:1771-80.

41 Kluzek S, Sanchez-Santos MT, Leyland KM, et al. Painful knee but not hand osteoarthritis is an independent predictor of mortality over 23 years follow-up of a population-based cohort of middle-aged women. Ann Rheum Dis 2016;75:1749-56.

42 Liu R, Kwok WY, Vliet Vlieland TPM, et al. Mortality in osteoarthritis patients. Scand J Rheumatol 2015:44:70-3.

43 Mendy A, Park J, Vieira ER. Osteoarthritis and risk of mortality in the USA: a population-based cohort study. Int J Epidemiol 2018;47:1821-9.

44 Nüesch E, Dieppe P, Reichenbach S, et al. All cause and disease specific mortality in patients with knee or hip osteoarthritis: population based cohort study. BMJ 2011;342:d1165.

45 Rahman MM, Kopec JA, Anis AH, et al. Risk of cardiovascular disease in patients with osteoarthritis: a prospective longitudinal study. Arthritis Care Res 2013:65:1951-8.

46 Tsuboi M, Hasegawa Y, Matsuyama Y, et al. Do musculoskeletal degenerative diseases affect mortality and cause of death after 10 years in Japan? J Bone Miner Metab 2011;29:217-23.

47 Turkiewicz A, Kiadaliri AA, Englund M. Cause-Specific mortality in osteoarthritis of peripheral joints. Osteoarthritis Cartilage 2019;27:848-54.

48 Veronese N, Cereda E, Maggi S, et al. Osteoarthritis and mortality: a prospective cohort study and systematic review with meta-analysis. Semin Arthritis Rheum 2016;46:160-7.

49 Veronese N, Stubbs B, Solmi M, et al. Osteoarthristis increases the risk of cardiovascular disease: data from the osteoarthritis initiative. J Nutr Health Aging 2018;22:371-6

50 Veronese N, Trevisan C, De Rui M, et al. Association of osteoarthritis with increased risk of cardiovascular diseases in the elderly: findings from the Progetto Veneto Anziano study cohort. Arthritis Rheumatol 2016;68:1136-44.

51 Watson DJ, Rhodes T, Guess HA. All-Cause mortality and vascular events among patients with rheumatoid arthritis, osteoarthritis, or no arthritis in the UK general practice research database. J Rheumatol 2003;30:1196-202.
52 Liu Q, Niu J, Li H, et al. Knee symptomatic osteoarthritis, walking disability, NSAIDs use and all-cause mortality: population-based Wuchuan osteoarthritis study. Sci Rep 2017;7:3309.

53 Wang Y, Nguyen U-SDT, Lane NE, et al. Knee osteoarthritis, potential mediators, and risk of all-cause mortality: data from the osteoarthritis initiative. Arthritis Care Res 2020. doi:10.1002/acr.24151. [Epub ahead of print: 21 Jan 2020].

54 Pottier P, Hardouin JB, Lejeune $\mathrm{S}$, et al. Immobilization and the risk of venous thromboembolism. A meta-analysis on epidemiological studies. Thromb Res 2009;124:468-76.

55 Kearon C, Ageno W, Cannegieter SC, et al. Categorization of patients as having provoked or unprovoked venous thromboembolism: guidance from the SSC of ISTH.J Thromb Haemost 2016;14:1480-3.

56 Lear SA, Hu W, Rangarajan S, et al. The effect of physical activity on mortality and cardiovascular disease in 130000 people from 17 high-income, middle-income, and low-income countries: the PURE study. Lancet 2017:390:2643-54.

57 Mok A, Khaw K-T, Luben R, et al. Physical activity trajectories and mortality: population based cohort study. BMJ 2019:365:12323.

58 Ekelund U, Tarp J, Steene-Johannessen J, et al. Dose-Response associations between accelerometry measured physical activity and sedentary time and all cause mortality: systematic review and harmonised meta-analysis. BMJ 2019;366:14570

59 National Clinical Guideline Centre (UK). Osteoarthritis: care and management in adults, 2014. Available: https://www.ncbi.nlm.nih.gov/books/NBK248069/pdf/ Bookshelf_NBK248069.pdf [Accessed 8 Nov 2019].

60 Bannuru RR, Osani MC, Vaysbrot EE, et al. OARSI guidelines for the non-surgical management of knee, hip, and polyarticular osteoarthritis. Osteoarthritis Cartilage 2019;27:1578-89.

61 Kolasinski SL, Neogi T, Hochberg MC, et al. 2019 American College of Rheumatology/ Arthritis Foundation guideline for the management of osteoarthritis of the hand, hip, and knee. Arthritis Rheumatol 2020;72:220-33.

62 Price AJ, Alvand A, Troelsen A, et al. Knee replacement. Lancet 2018;392:1672-82.

63 Ferguson RJ, Palmer AJ, Taylor A, et al. Hip replacement. Lancet 2018:392:1662-71. 